
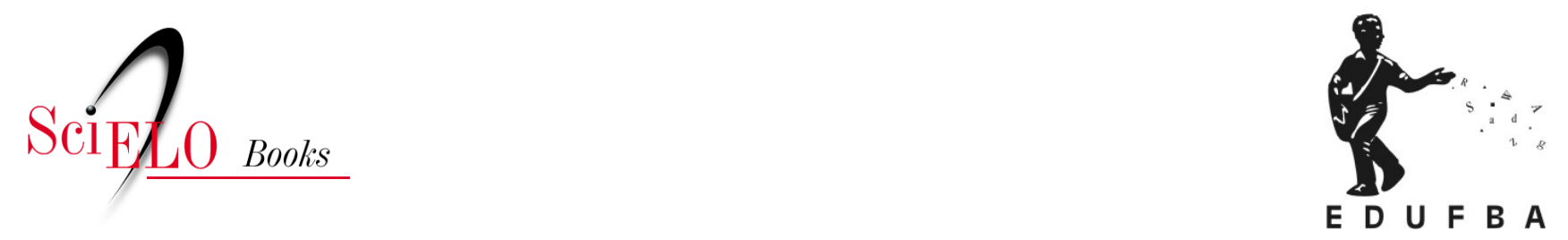

\title{
Natureza, ilustração e paisagismo estudo iconográfico das representações dos viajantes William John Burchell e Auguste François Marie Glaziou no Brasil do século XIX
}

\author{
Maria de Fatima Hanaque Campos \\ Mariana Reis de Brito
}

\section{SciELO Books / SciELO Livros / SciELO Libros}

CAMPOS, M.F.H., and BRITO, M.R. Natureza, ilustração e paisagismo: estudo iconográfico das representações dos viajantes William John Burchell e Auguste François Marie Glaziou no Brasil do século XIX. In: HERNÁNDEZ, M.H.O., and LINS, E.Á., eds. Iconografia: pesquisa e aplicação em estudos de Artes Visuais, Arquitetura e Design [online]. Salvador: EDUFBA, 2016, pp. 168-187. ISBN: 978-85-232-1861-4. https://doi.org/10.7476/9788523218614.0011.

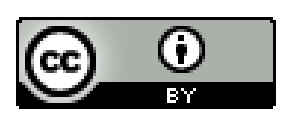

All the contents of this work, except where otherwise noted, is licensed under a Creative Commons Attribution $\underline{4.0 \text { International license. }}$

Todo o conteúdo deste trabalho, exceto quando houver ressalva, é publicado sob a licença $\underline{\text { Creative Commons }}$ Atribição 4.0. 
Natureza, ilustração e paisagismo: estudo iconográfico das representações dos viajantes William John Burchell e

Auguste Françoís Marie Glaziou no Brasil do século XIX

Maria de Fatima Hanaque Campos

Mariana Reis de Brito 


\section{Introdução}



estudo da flora brasileira tem início no século XVII e se intensificou no século XIX, após a chegada da Família Real ao Brasil e a abertura dos nossos portos. De vários países da Europa, chegaram naturalistas com o objetivo de conhecer o potencial de utilização dos nossos recursos. A literatura e registros iconográficos de viajantes do século XVIII e XIX no Brasil têm sido fontes de informação para muitos estudos da história cultural, das ciências e das artes, que conferem ao sujeito uma atitude ativa, investigativa, criadora no olhar e de compreensão da alteridade, ou seja, do modo como ele olha os mundos descobertos e visitados.

Como exemplos dos viajantes que vieram para o Brasil com o intuito de investigar e registrar a exuberante natureza dos trópicos, podem ser lembrados: Maximiliano de Wied-Neuwied (1815-1818); Auguste de Saint-Hilaire (18161822); Spix e Von Martius (1817-1820); Maria Graham (1821); William John Burchell (1825-1829); Charles Darwin (1832); Conde de Suzannet (1842-43); Conde de Castelnau (1848-55); George Gardner (1836-41); Auguste François Marie Glaziou (1858-1897); dentre outros.

Os viajantes vieram ao Brasil, durante os séculos XVIII e XIX, com roteiros organizados, e suas viagens cobriram diferentes partes do território brasileiro. 
Produziram obras a partir do contato direto com o objeto investigado, de modo a conceder um tratamento científico aos objetos de investigação. Esse acervo de imagens, textos e coleções de plantas foi depositado em museus e herbários europeus para posterior publicação e circulação de obras literárias ou científicas.

O nosso objeto de estudo é a produção material e artística de dois viajantes do século XIX: William John Burchell (1781-1863) e Auguste François Marie Glaziou (1828-1906). Pretendemos reconstituir suas atuações em solo brasileiro, esclarecendo como esses personagens observaram e registraram o espaço e a natureza do Brasil.

A metodologia utilizada para realizar esse estudo partiu de fontes bibliográficas e documentais, dando ênfase aos acervos de William John Burchell e Auguste François Marie Glaziou. A documentação produzida pelos viajantes encontra-se, em sua maioria, depositada em bibliotecas e arquivos nacionais e nos herbários europeus, iniciando-se por aqueles mais representativos, Royal Botanic Gardens (K), em Kew, Reino Unido, e Muséum National d'Histoire naturelle (P), em Paris, França. A contribuição desses viajantes tem sido de grande importância para estudos interdisciplinares.

O texto inicia-se com considerações sobre o tratamento da natureza como objeto de estudo das ciências naturais e como propulsor das artes, bem como sobre os viajantes como sujeitos criadores. Em seguida, são discutidas as formações de Burchell e Glaziou e suas atuações como botânicos, bem como suas viagens ao Brasil e suas coleções de plantas e obras artísticas, as quais serão aqui analisadas. Ao término deste texto, são apresentadas as considerações finais.

\section{A natureza como objeto de estudo das ciências naturais e propulsora das artes e os naturalistas como sujeitos criadores}

Segundo Arber (1912), na Idade Média, o conhecimento da botânica aristotélica foi trazido para a Europa ocidental. Rhabanus Maurus (780-856), abade beneditino, compilou uma enciclopédia que continha informações sobre plantas, indiretamente derivadas dos escritos de Theophrastus (371-287 a. C.), discípulo de Aristóteles. A concepção de base filosófica ainda predominava no campo das ideias e da natureza das coisas.

A autora considera que o estudo das plantas teve maior atenção com a medicina, que buscava conhecer várias plantas antigas e os tipos utilizados para fins diferentes. Acrescenta-se a atuação dos herbalistas e farmacêuticos, que fizeram um negócio regular de coleta, preparação e venda de plantas.

Segundo Arber (1912), após a invenção da imprensa (1439), seguiu-se um período muito ativo de produção de livros, durante o qual muitas obras que haviam passado anteriormente uma existência mais ou menos longa como os manuscritos 
foram colocadas em circulação simultaneamente com livros realmente escritos na época. Entre os primeiros trabalhos europeus existentes sobre o uso de plantas medicinais, está Materia Medica, de Dioscórides (50-70 d.C.), que incluia páginas ilustradas identificando as características de algumas plantas. Apresenta 600 plantas úteis e foi usado na farmacopeia europeia até o século XIX.

Lamy (2008) cita vários tratados de botânica como Rariorum aliquot stirpium (1576); Rariorum Plantarum (1601); ilustrado com mais de 1000 gravuras; Plantes usuelle, indigenes et exotique, dessinées et coloriés d'apres nature (1807-1808), que utilizaram do desenho como prova de observação, antes da palavra, como suporte da taxonomia.

Com o Renascimento, as ciências e as artes vão ter grande impulso com a releitura de obras clássicas e a utilização de técnicas de representação tridimensional da imagem, como a perspectiva, que contribuiu para a obtenção de sentido de realidade através de elementos da natureza e de paisagens nas pinturas da época. Arber (1912) considera que o desenho contribuiu para o conhecimento e registro da natureza, pois o trabalho do artista pode aumentar a percepção com tons delicados de diferença ou semelhança da forma, tendo o olhar do botânico a supervisionar seus esforços. Ainda havia limitações nas descrições, e a imagem contribuia nesse propósito.

Segundo Prestes, Oliveira e Jensen (2009), o interesse no conhecimento das plantas foi crescendo na Europa a partir do contato direto com a natureza e as espécies exóticas coletadas com as grandes navegações, tanto no Oriente quanto no Novo Mundo. Em consequência, o conhecimento se ampliou na busca de classificações das espécies.

Beinart e Midleton (2009) consideram que a história das plantas teve contribuição dos cientistas botânicos ocidentais e do desenvolvimento de instituições de caráter científico e cultural.

Sanjad (2001) corrobora com as iniciativas de reis e papas não só na construção de grandiosos palácios pelas cortes da Itália, França e Inglaterra, mas também em jardins botânicos ou jardins físicos surgidos em Pisa (1543) e Pádua (1545) e, depois, em outras cidades europeias, como Montpellier (1598), Oxford (1621) e Edinburgh (ca. 1670), ou como estabelecimentos reais, como foi o caso do Jardim Real de Plantas Medicinais, em Paris (1640). Nesse sentido, a atuação dos naturalistas foi fundamental no desenvolvimento das inúmeras instituições culturais.

Prestes, Oliveira e Jensen (2009) consideram que o conhecimento na área da botânica foi construído por vários estudiosos que utilizaram sistema de classificação antes de Carl Lineu (1707-1778).

Para Stearn (1957), o sistema de Lineu possibilitou aos iniciantes um método mais acessível de estudar as plantas, principalmente para os interessados em 
viajar com a crescente penetração europeia nos trópicos e a exploração botânica mais intensiva. Dessa forma, foi possível identificar as plantas mais apropriadas, aclimatá-las em novos espaços e manejá-las para aumentar a produção.

Allain (2008) considera que o transporte de plantas se achava em todos os portos de cidades com forte poder comercial, como Londres, Lisboa, Cadix e Trieste. Todos os vegetais chegavam aos portos em quantidade, depois seguiam por rotas terrestres para se transformarem em "Jardins do Éden".

Sanjad (2001) afirma que, no final do século XVII, já era perceptível a separação de duas atividades, até então, correlatas: o desenho e a conservação dos jardins. A primeira atividade continuou a cargo de paisagistas, arquitetos e virtuosos, os quais seguiram cada vez mais se utilizando de árvores, plantas e flores - valorizadas de acordo com seu exotismo, variedade de cores e formato - para a ornamentação dos espaços livres, no qual o jardim do Palácio de Versalhes, a partir de 1661, é um bom exemplo. Por sua vez, no jardim, com propósitos experimentais ou pedagógicos, o desenho passou a obedecer a uma racionalidade própria, assim como a conservação das plantas, determinada, agora, pelos profissionais que estabeleceram os critérios que distinguiriam jardins e museus no século seguinte.

Stearn (1957) ressalta a importância do desenvolvimento dos estudos diretamente com as plantas realizados nos herbários. No século XVIII, a palavra "herbário" era mantida no seu uso original sobre plantas medicinais, e foi "Tournefort", em 1700, que o usou como equivalente ao hortus siccus (jardim de plantas secas); durante o século, em grande parte, através da influência de Lineu, esse termo foi utilizado para uma coleção de plantas prensadas e secas, fixadas em papel para registro botânico. Esse dado é importante, pois os viajantes Burchell e Glaziou, além de desenvolverem atividades no campo das artes, como desenhos, aquarelas e projetos paisagísticos, também organizaram coleções de espécies, formando herbários como fonte para o estudo da flora brasileira.

\section{Visões do Brasil: desenho e paisagismos nas representações da natureza dos viajantes-naturalistas Burchell e Glaziou}

Os viajantes estrangeiros buscavam desvendar a natureza tropical para a produção de conhecimento científico, literário, econômico e artístico. Kury (2001) analisa alguns viajantes naturalistas que vieram ao Brasil e que tinham influência de Friedrich Wilhelm Heinrich Alexander von Humboldt (1769-1859). Esse botânico considerava o contato direto com a natureza e as impressões estéticas experimentadas em cada região como parte da atividade científica. Dessa forma, as sensações visuais experimentadas acompanhavam, sempre que possível, os relatos e descrições feitos pelo naturalista. 
Campos (2006) considera que as imagens criadas por naturalistas ou artistas que se integravam às expedições eram baseadas na imitação de modelos clássicos, da perfeição das formas e da técnica. O desenho guiava-se a partir da imitação de estampas que representavam elementos da natureza, dos corpos que deviam ampliar a ideia de beleza.

Nesse sentido, os naturalistas Burchell e Glaziou, apesar de terem origens e formação diferenciadas, deram importância à aquisição de conhecimentos através do contato com a natureza de outros continentes. Assim, eles puderam ter experiências de diversas formas, tanto voltadas para a ciência como para a arte.

Para a análise das imagens dos naturalistas, a documentação foi organizada de forma serial, transcrita e fotografada. Procedeu-se de forma qualitativa e quantitativa, observando os dados comuns às coleções de Burchell e Glaziou, assim como se buscaram especificidades, verificando diferenças que ocorrem motivadas pelo tempo ou por aspectos sociais e culturais. As fontes iconográficas analisadas foram desenhos e pinturas de Burchell e uma obra paisagística de Glaziou, todas realizadas em solo brasileiro. Iniciou-se com a identificação e sistematização das formas, técnicas e textos contidos nas obras analisadas. Seguiu-se o pressuposto de que as imagens artísticas serviam para compor o texto, buscando uma complementaridade.

Nos tratados de botânica consultados, verificou-se o uso da descrição das plantas através dos textos e gravuras, contribuindo para maior reconhecimento da diversidade das espécies. Entretanto, o conhecimento de classificação das plantas dá um salto qualitativo com Lineu. Segundo Stearn (1957), o botânico iniciou esta classificação no livro Species Plantarum (1753), por forma metódica e consistente.

Essa obra de Lineu foi utilizada por Burchell durante o seu trabalho de coleta e anteclassificação, como também na descrição taxonômica dos vários elementos constituintes das espécies e na representação das mesmas através dos seus desenhos. Os modelos de seccionar as partes das plantas de Lineu são utilizados por Burchell na representação da espécie Royena lucida (Figura 1). Para a análise da representação da cidade do Rio de Janeiro, vista panorâmica realizada por Burchell, observou-se o uso da técnica topográfica para maior conhecimento dos solos e conformações geográficas, úteis aos desenhistas que seguiam as expedições naturalistas. A identificação dos recursos naturais e de construções urbanas compunha o ambiente visto e descrito com textos e imagens.

Partiu-se de dados biográficos dos naturalistas para maior entendimento da sua formação educacional e profissional e de sua trajetória nas ciências e nas artes. $\mathrm{O}$ aprendizado se dava através de conhecimentos teóricos e práticos no campo das ciências naturais. Nesse sentido, o desenho auxiliava no reconhecimento 
dos elementos da natureza de forma. O desenho perderá sua eficácia, no final do século XIX, com o uso de microscópio.

William John Burchell nasceu em 23 de julho de 1781, em Fulham, Londres. O negócio da família foi estabelecido no reinado de George I, e é normalmente referido como "viveirista", e que foi assumido por longo tempo. Ocupava cerca de sete hectares e meio, no lado sul da Kings Road, Fulham, sendo muito rentável e contribuindo com o Kew Gardens, na mudança de amostras e resultados da investigação.

Segundo Les Cleverly ([1987]), a formação de William Burchell foi esmerada em Raleigh House Academy, em Mitcham, Surrey. Ele tinha capacidade intelectual e foi igualmente dotado de línguas, ciência e arte, uma combinação rara. Aos 13 anos, Burchell foi apresentado a um mestre de botânica e de latim e pôde ter contato livros avançados, incluindo obras de Lineu, como System of Botany. Aos 15 anos, ele recebeu formação em arte por Merigute, através de um desenhista topográfico, John Claude Matts, eminente em seu campo.

Ele continuou seus estudos botânicos, inclusive no Kew Gardens, onde muitos dos espécimes de plantas exóticas foram, mais tarde, alojados. Lá, ele conheceu muitos botânicos importantes de várias partes do mundo, e viajou por toda a Inglaterra, País de Gales e Escócia, com interesses nas ciências naturais.

Aos 22 anos, foi nomeado membro da Linnean Society. Seu pai esperava que ele entrasse no negócio da família após a sua formação educacional, particularmente pela sua integração à qualidade de membro da referida associação científica, mas Burchell desejava fazer viagens e explorações em outros continentes.

Segundo Mckay (1941), Burchell foi um naturalista, observador da natureza em muitos aspectos, mas essas atividades estavam no campo da botânica, no qual ele seria reconhecido, e este trabalho pode ter quatro divisões: primeiro, sua permanência em Santa Helena; segundo, com sua jornada em África do Sul; terceiro, o seu período de permanência em terras brasileiras; e quarto, o período europeu e seu contato com outros botânicos.

A obra pictórica do botânico e artista está relacionada à sua atividade de contato e conhecimento da natureza e das grandes excursões realizadas: Santa Helena (1805-1810), África do Sul (1810-1815) e Brasil (1825-1830). Os desenhos produzidos na viagem à Santa Helena contaram em torno de 500, que se encontram depositados no Royal Botanic Garden, em Kew, Inglaterra, juntamente com seu herbário, os quais tivemos acesso e, portanto, iremos analisar alguns aspectos dessa coleção. Da viagem à África do Sul, ele produziu desenhos que foram utilizados para ilustrar o seu livro Travels in the interior of South Africa. A viagem ao Brasil produziu desenhos e aquarelas. Iremos analisar alguns aspectos dessa produção. 
Sobre a viagem ao Brasil, Bethel (2012) estudou sobre dois artistas ingleses, considerando Charles Landseer como jovem artista e William J. Burchell como botânico e artista amador. Afirmou que a vinda dos artistas estava ligada à missão diplomática britânica, chefiada por Sir Charles Stuart, encarregado de negociar o reconhecimento, por parte de Portugal e Grã-Bretanha, do recém-independente Império do Brasil. Segundo o autor, na estadia dos artistas, Landseer produziu 150 desenhos, e Burchell, 230 desenhos e aquarelas sobre o Brasil. Ele reflete também sobre o valor artístico e iconográfico de suas obras, trazendo uma complexa história das coleções e concluindo que os desenhos de Burchell foram doados pela família e estão no Museu África, em Johannesburgo, África do Sul, enquanto os desenhos de Landseer estão no Instituto Moreira Sales no Rio de Janeiro.

Segundo Carvalho (2013), Burchell começou a formular o seu método de trabalho artístico ainda muito jovem, na Inglaterra, e em viagens de férias no País de Gales, ocasiões nas quais, ao lado da coleta de espécimes botânicos, desenhava. Maior amadurecimento seria obtido em suas longas expedições, quando veio a estabelecer um vínculo único entre as ciências e a arte.

A partir da viagem a Santa Helena (1810-1815), produziu um conjunto de desenhos que se encontra organizado por temas, como marinhas, cenas campestres, registro da flora local e, por fim, o uso do desenho para contributo ao conhecimento da taxonomia. O objetivo do artista era tanto registrar as suas impressões da natureza, como também da sua estadia na ilha. $\mathrm{Na}$ sua maioria, foram feitos em lápis e crayon, sem uso de recurso de cores, à exceção das fisionomias topográficas da ilha e das representações de espécies de plantas como recurso taxonômico.

Os desenhos sobre cenas campestres foram feitos com recursos de perspectiva, demonstrando o domínio na apreensão dos detalhes de formas e objetos. Destacam-se as representações da flora da Ilha de Santa Helena como recurso ao estudo taxonômico, no qual foram utilizados, ao lado das imagens, textos para a identificação das espécies.

Como exemplo de um desses desenhos, foi selecionado o que registra uma espécie denominada Royena lucida (Figura 1) ${ }^{1}$ - arbusto ou árvore pequena com folhas elípticas, com tons de verde escuro. As flores, em formatos elípticos e fechados, são também apresentadas em corte para visualizar o cálice e pistilos. Estes elementos denotam as estruturas de crescimento e reprodução da espécie.

Vale destacar que o modelo de representação já foi utilizado por Joseph Pitton de Tournefort (1656-1708), que publicou Elementos da Botânica (1694) e

1 Reproduzida a imagem com a permissão do Diretor e do Conselho de Curadores, Royal Botanic Gardens, Kew. 
propôs um sistema formado por 700 gêneros de plantas, classificadas com base nos caracteres da flor, especificamente da corola. Essa obra, fundamental para a botânica, propôs métodos de identificação das espécies e incluiu ilustrações científicas para demarcar semelhanças e diferenças entre as espécies. (PRESTES, OLIVEIRA, JENSEN, 2009) O desenho de Burchell tinha o objetivo de auxiliar a identificação da espécie encontrada, distinguindo o formato das folhas, flores, frutos, além de colocar cortes longitudinais para o conhecimento dos elementos internos da espécie. Assim, o desenho ampliava os recursos para a identificação taxonômica.

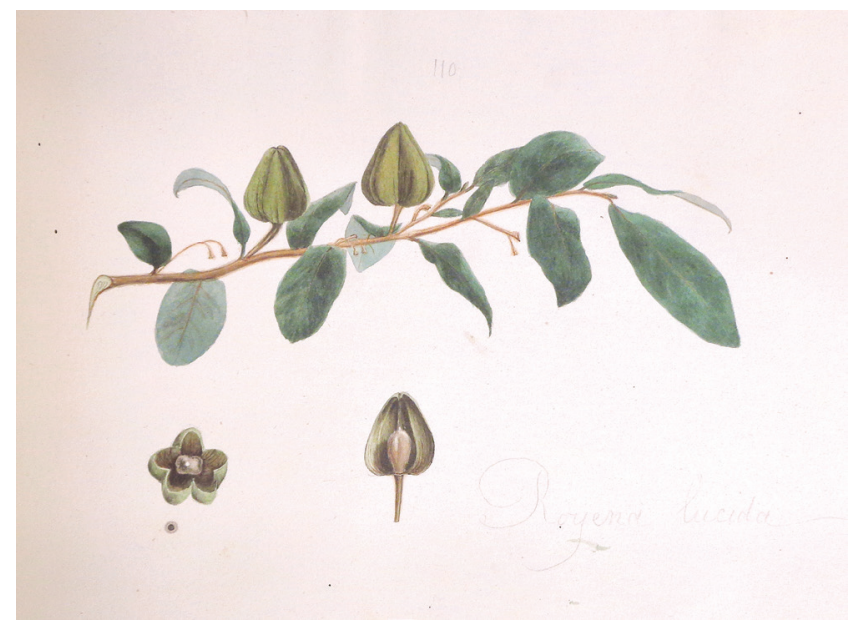

Figura 1 - Royena lúcida, de William J. Burchell Fonte: Acervo do Royal Botanic Garden Kew.

Carvalho (2013) considera que Burchell criou imagens, enquanto permaneceu na Ilha de Santa Helena, de grande expressividade, mas também com uma delicadeza subjacente, além de acuidade visual que captou e localizou com precisão a função exata de cada elemento retratado, os quais acompanhavam as coleções e notas científicas correlatas do seu herbário.

Para Kury (2001), alguns botânicos tiveram uma impressão de impacto no contato com a natureza exuberante dos trópicos, e em especial do Brasil. Como exemplo, cita o botânico Carl Philip Von Martius, que foi um dos seguidores das experiências de Humboldt, pois descreveu com sensibilidade diversas fisionomias vegetais presentes no Brasil. Em várias obras, retratou a variedade da vegetação, do relevo e da fauna no Brasil. Buscava retratar as suas espécies estudadas a partir de três registros diferentes: aspectos morfológicos, ambiente natural e aspectos geográficos e geológicos. 
A autora salienta, ainda, que a representação da fisionomia e detalhes dava conta da descrição detalhada das partes componentes da planta, essencial para a classificação e compreensão do seu desenvolvimento; a paisagem compunha de elementos conjuntos como homem e natureza. A variedade de registros que se originaram da observação e da pesquisa de um determinado fenômeno inclui, no caso da viagem de Spix e Martius ao Brasil, o tratamento da natureza como conjunto de indivíduos, animais e vegetais, tratados pelos métodos científicos que se atêm aos detalhes. Assim, os relatos dos viajantes, produzidos no contato com a natureza, seguiam pressupostos científicos, mas a subjetividade inerente às experiências vividas resultava em maneiras diferenciadas de apresentar a natureza.

$\mathrm{Na}$ viagem ao Brasil, Burchell produziu vários desenhos, e alguns destes têm sido fonte iconográfica para estudos acadêmicos na área de histórica regional, da arquitetura, com destaque ao conhecimento da paisagem brasileira no século XIX. O valor de registro documental foi ressaltado por Salgado e Piccinato Junior (2012), que incluíram um desenho do artista sobre Vila Franca do Imperador, feito em 1827; Franklin (2005) destacou o desenho do artista, feito em 1829, sobre uma embarcação típica do rio Tocantins; Oliveira (2013) e Luz (2012) reconstituíram a paisagem colonial através de um desenho de Burchell, feito em 1828, da vista geral da Vila Boa de Goiás. Da mesma forma, foi realizado um estudo comparativo sobre a Capela do Carvalho, em Santos, tendo como uma das referências um desenho do artista, datado de 1826. Tognon (2011), ao estudar os desenhos da arquitetura colonial brasileira, destacou o seu valor documental e incluiu as obras de Burchell e Rugendas como as melhores. Segre e colaboradores (2009) estudaram o desenho como hiperdocumento iconográfico da história da cidade do Rio de Janeiro, incluindo uma panorâmica de artista.

Perrota (2011, p. 43) considera que as representações da paisagem brasileira feitas pelos viajantes são de uma complexidade documental chamada de iconografia de viagem e reconhecida como registro documental. Essas imagens eram complexas, pois guardavam a função de ilustrar relatos de viagens; na sua maioria, guardavam interesses de registro de perfis e marcos litorâneos, mapeamentos de espécies botânicas desconhecidas, paisagem construída, etnografia, hábitos e costumes, construção do exótico. Essa variedade de interesses podia também ter representações com um delineamento mais estético, como também de um delineamento de uma fidelidade absoluta.

Poulton (1907) analisou as atividades do viajante-naturalista e, sobre as suas experiências no Brasil, transcreveu algumas cartas escritas por Burchell ao seu amigo Sir William Hooker a respeito das principais linhas de seu trabalho no Rio de Janeiro. Durante os anos de 1825 e 1826, realizando atividades de coleta para formação da sua coleção de botânica, entomologia e geologia e, ao mesmo tempo, fazendo alguns desenhos de paisagem, entre os quais existia um panorama 
tirado de uma colina no meio da cidade, reuniu muitas observações astronômicas, filosóficas e geodeticais. Destaca o botânico que os encantos da natureza produziam a descoberta de novos objetos e o interesse de acumular coleções de objetos curiosos.

Ferrez (1966), ao analisar as paisagens do referido artista, realizadas em julho de 1825 , teceu alguns comentários nas suas cartas a familiares, ressaltando as riquezas botânicas do país, comparando a uma das maiores estufas da natureza, a exuberância, as formas exóticas, que faziam Burchell, muitas vezes, deixar a história natural pela pintura.

Os trabalhos pictóricos, analisados por Ferrez (1966), foram cedidos pela Universidade de Witwatersrand, em Johannesbrug. Destacam-se representações da cidade do Rio de Janeiro e uma tomada circular do velho forte de São Sebastião, no Morro do Castelo, executada no topo do Castelo Hill. Para o autor, dos vários panoramas da cidade do Rio de Janeiro feitos no século XIX, o de Burchell não é apenas o mais preciso, mas o melhor, com uma perspectiva correta, fiel à arquitetura, relatando uma série de informações, como ruas, prédios, igrejas, montanhas e ilhas. Acompanhava o panorama um extenso índice remissivo com identificação dos principais prédios públicos e religiosos, acidentes geográficos e exemplares botânicos também enumerados. Demonstrou, dessa forma, ser um profundo observador da natureza in loco.

Perrota (2011) considera as vistas panorâmicas como uma técnica formada por uma sequência de desenhos apresentados lado a lado ou constituindo-se uma imagem de 360 graus, apresentada de uma forma circular. Os quadros eram tomados de diferentes pontos de vista, a partir de uma mesma localização central. Vários artistas fizeram vistas panorâmicas sobre o Rio de Janeiro, mas foi Burchell que recebeu o título de "O mais belo panorama do Rio de Janeiro", com uma vista circular tomada do alto do morro do Castelo. São oito folhas de 37x 54 $\mathrm{cm}$ cada, formando um círculo cujo comprimento linear de $432 \mathrm{~cm}$.

Segundo Carvalho (2013), os registros e coleções foram produzidos inicialmente no Rio de Janeiro, Minas Gerais, na exploração da costa sudeste, depois, retornando ao Rio de Janeiro em direção à Serra dos Órgãos e Santos, e, ao atravessar o país de São Paulo a Belém do Pará, passando pela árida savana do planalto central. $\mathrm{O}$ objetivo das expedições do artista e naturalista era atravessar regiões desconhecidas e inexploradas, realizando um amplo e diversificado inventário ambiental e registrando tudo o que fosse peculiar a habitantes e modos de vida autóctones. Sua intenção, pode-se dizer, era reconstruir natureza e cultura, criando descrições em desenhos, pinturas e escritos sobre paisagens que, de acordo com sua visão e valores, seriam apresentados ao público e comunidade científica inglesa. 
Auguste François Marie Glaziou nasceu em Lannion, na região da Bretanha, França, no dia 30 de agosto de 1828. Proveniente de uma família humilde, Glaziou iniciou sua aprendizagem em jardinagem e horticultura com o pai. Ao completar 16 anos, deixou sua cidade natal e partiu para uma longa viagem pela França, realizando cursos de botânica, como o do Museu de História Natural de Paris, onde aprofundou seus conhecimentos em agricultura e horticultura. Sua paixão pelas plantas o levou ao paisagismo, especializando-se em paisagismo urbano. (CUNHA, 2007)

Aos 30 anos de idade, desembarcou no Brasil em busca de oportunidades profissionais e conhecimento da natureza dos trópicos. Glaziou teve a oportunidade de conhecer o deputado Francisco José Fialho e, a partir deste momento, seu destino começa a ser traçado. Fialho acabara de ser encarregado pelo Imperador Dom Pedro II de idealizar uma série de melhorias urbanas para a capital brasileira, onde parques e jardins assumiriam uma grande proporção. Dentre esses avanços, estava a reforma do Passeio Público. Glaziou, por apresentar conhecimentos em horticultura e experiências na França, foi escalado, em 1860, para essa nova empreitada, o que lhe rendeu ótimos frutos profissionais, estabelecendo uma boa relação com o Imperador. (MÉRIAN, 2009)

Em 1869, Dom Pedro II o convidou para coordenar a Diretoria Geral de Matas e Jardins da Casa Imperial, no Rio de Janeiro. Acumulou também o cargo de Inspetor dos Jardins Municipais, além de integrar a Associação Brasileira de Aclimação. (NORONHA, 1944a)

Os postos que assumiu, juntamente com sua aproximação com o Imperador, lhe permitiram estar ligado à maior parte dos importantes projetos paisagísticos acontecidos na Corte durante o Segundo Império. (CASADEI, 1985) Além dos jardins e parques públicos, realizou também obras privadas, como os jardins das residências das princesas imperiais, da família do Barão de Nova Friburgo, do Barão de Mauá e da família Tavares Guerra. Atribui-se a ele a autoria de muitos outros jardins, mas a falta de documentação leva a inúmeras discussões. (AMADURO, 2009)

Sanjad (2001), ao estudar a instalação do Jardim Botânico do Grão Pará (1796-1873), destaca a decisão da Coroa Portuguesa de criar os jardins coloniais como reflexo da conjuntura política e econômica da Europa e da América, de maneira a difundir as plantas por todo o império lusitano e adaptá-las a diferentes terrenos e climas. Ressalta, ainda, as exigências salubristas do Século das Luzes que interferiram na urbanização das cidades coloniais do Brasil, colocando à natureza e ao cultivo das plantas uma utilidade saneadora e higienizadora dos ambientes. 
Quanto à elaboração de grandes jardins públicos no Brasil, somente a partir do século XVIII surge a preocupação em executá-los, com o intuito de estimular a experiência prazerosa de se estar em contato com a natureza. (TERRA, 2000)

Um dos primeiros jardins públicos construídos no Brasil foi o Passeio Público, no Rio de Janeiro. O parque foi encomendado por D. Luis de Vasconcelos, que incumbiu o Mestre Valentim de projetar um jardim público, voltado para servir à população da cidade, estimulando-a para o sentido da beleza, da satisfação e do prazer. Sua obra foi iniciada em 1779 e sua inauguração ocorreu quatro anos mais tarde. Para atender às preocupações de ordem higiênica, que começaram a ser introduzidas neste período, o artista e urbanista optou por aterrar a Lagoa Grande com o desmonte do outeiro das Mangueiras. Este seria o primeiro jardim estruturado às proximidades do contexto urbano. (VALENTE et al., 1979) Tal espaço, inspirado nos jardins racionalistas franceses, existiu até a década de 1860, quando foi transformado pela reforma implementada pelo paisagista Auguste François Marie Glaziou, que concebeu para o Passeio um traçado ao gosto dos jardins românticos ingleses.

A chegada da Família Real ao Brasil estimulou uma nova sensibilidade à natureza e uma nova mentalidade na arte do paisagismo. A necessidade de uma corte organizada, de acordo com os padrões europeus, e a vinda da Missão Artística Francesa transformaram a concepção da arte de execução dos jardins. (TERRA, 2000) Vários costumes europeus foram introduzidos na cidade do Rio de Janeiro, que passou pelas mais rápidas e urgentes transformações urbanas e, em 1822, tornou-se a capital de uma nova nação. (MACEDO; SAKATA, 2002) Dentre as iniciativas de D. João, destaca-se a criação do Real Horto, atualmente Jardim Botânico do Rio de janeiro, cujas finalidades eram a aclimatação, o cultivo de plantas exóticas e raras, além de árvores de interesse comercial e industrial. (MILANO; DALCIN, 2000)

Em meados do século XIX, firma-se um novo conceito urbano no Brasil Império, baseado nos critérios de higienização, funcionalidade e embelezamento. A falta de higiene dos locais públicos e das habitações passou a ser uma grande inquietação de profissionais como engenheiros e médicos. Segundo Lemos (1999), as condições insalubres em que se apresentavam as habitações eram de verdadeira promiscuidade.

De acordo com esses novos preceitos, inicia-se uma série de reformas urbanísticas e sanitárias através da construção de praças e jardins públicos, com a finalidade de serem áreas destinadas às atividades de recreação, contemplação da natureza e convivência social. A integração dos elementos da flora na composição da cidade também ajudou a solucionar o problema do adensamento urbano. Deste modo, as áreas ajardinadas passam a constituir um elemento importante nos espaços livres, e observa-se, neste período, uma grande apreciação pelas 
áreas verdes. A população começa a criar o hábito da jardinagem, valorizando e utilizando a vegetação para o embelezamento da cidade e as classes média e alta alimentam o desejo de vida mais simples e em maior harmonia com a natureza. (ROBBA; MACEDO, 2002)

A chegada da Missão Artística Francesa no Brasil, em 1816, foi responsável pelo início de um processo de inclinação ao neoclássico e de rompimento com o barroco, e nos projetos de Glaziou era possível observar essa lógica moderna, rompendo com os traçados retilíneos do jardim barroco francês e introduzindo, em seu lugar, os traços sinuosos ingleses, que escondem recantos pitorescos e privilegiam diferentes pontos de vista, entre lagos, pontes, caramanchões, quiosques e mirantes, que inspiram a contemplação do cenário produzido. (FOLLY, 2007) Portanto, pode-se dizer que Glaziou, com sua relevante atuação, que se difundiu em diversos jardins, praças e parques, transformou a paisagem da capital brasileira na segunda metade do século XIX.

Segundo Terra (2000), a obra de Glaziou, se incluídos todos os jardins a ele atribuídos, pode ser dividida em três grupos distintos, de acordo com a existência ou não de documentação referente ao seu trabalho. O primeiro grupo foi definido a partir de opiniões, não documentadas, de alguns historiadores e da imprensa, e pode-se citar como exemplo a Praça Tiradentes, o Largo de São Francisco, os jardins do Palácio do Catete e o jardim da Casa da Marquesa de Santos, todos na cidade do Rio de Janeiro/RJ; o Jardim da Aclimação, em São Paulo/SP e o Parque do Museu Mariano Procópio, em Juiz de Fora/MG. Já o segundo grupo é constituído de projetos assinados ou documentos que mencionam a sua autoria, como os jardins do Palácio Imperial de Petrópolis/RJ; o Parque São Clemente (atual instituição privada Nova Friburgo Country Clube); a Praça Princesa Izabel, em Nova Friburgo/RJ; e a Praça D. Pedro II (atual Praça XV de Novembro), no Rio de Janeiro/RJ. E o terceiro e mais significativo grupo reúne obras que são comprovadamente de sua autoria, com ampla documentação: as reformas e as implantações do Passeio Público, o jardim da Quinta da Boa Vista e o Campo de Santana, todas localizadas na cidade do Rio de Janeiro, onde, ainda hoje, podem-se observar algumas de suas características originais.

Como característica do seu método de trabalho, Glaziou preocupava-se em representar a flora brasileira em seus projetos paisagísticos, algumas vezes agrupando-as de acordo com a zona climática a que pertenciam, de forma a constituir um verdadeiro mostruário da botânica nacional. (NORONHA, 1944b) $\mathrm{E}$, por isso, iniciou uma incessante busca por novas espécies ornamentais para aplicá-las em seus jardins. Viajou pelas restingas do estado do Rio de Janeiro, desde Cabo Frio até Parati. Explorou a Serra do Mar, a Serra dos Órgãos, na altura do alto Macaé e de Nova Friburgo, e o Pico do Itatiaia, em 1871. Além de integrar a comissão conhecida como "Missão Cruls", que partiu do Rio de 
Janeiro, em 9 de junho de 1892, em direção ao Planalto Central, com o objetivo de explorar o interior brasileiro e delimitar o lugar mais propício para a nova capital. (NORONHA, 1944a)

Através de suas expedições pelo país, chegou a coletar, entre o Rio de Janeiro, São Paulo, Minas Gerais e Goiás, 22770 espécimes, cujas exsicatas foram amplamente distribuídas entre os melhores e mais importantes herbários da Europa. Deve-se a ele a descoberta de diversas espécies novas para a ciência, cujos exemplares constituem-se em tipos nomenclaturais, em diversas famílias. A determinação de grande parte das espécies foi realizada por botânicos renomados daquela época, como Engler, Taubert, Eichler, Mez, Fée, Warming, Urban, entre outros. Muitos desses materiais foram citados na Flora Brasiliensis, de Von Martius (1840).

Entre 1860 e 1862, ocorreu a intervenção feita por Glaziou no Passeio Público do Rio de Janeiro. O projeto original do jardim foi realizado pelo escultor Mestre Valentim (1745-1813), em 1783. A renovação do Passeio Público foi a primeira atuação relevante de Glaziou em solo nacional e lhe rendeu grande visibilidade. A proposta não apenas equacionava a situação de desleixo que se alastrava sobre o mais antigo jardim público do Brasil, mas também substituía o traçado clássico do Mestre Valentin por uma composição calcada no vocabulário do jardim paisagístico moderno, que se tornaria pioneiro em espaços públicos brasileiros.

Analisando o desenho de Glaziou para o Passeio Público (Figura 2), é possível perceber que o paisagista europeu compreendeu que os cânones retilíneos da escola francesa estavam em desacordo com a sinuosidade da natureza brasileira. E, progressivamente, com sua relevante atuação, que se difundiu em diversos jardins, praças e parques, transformou a paisagem da capital brasileira na segunda metade do século XIX.

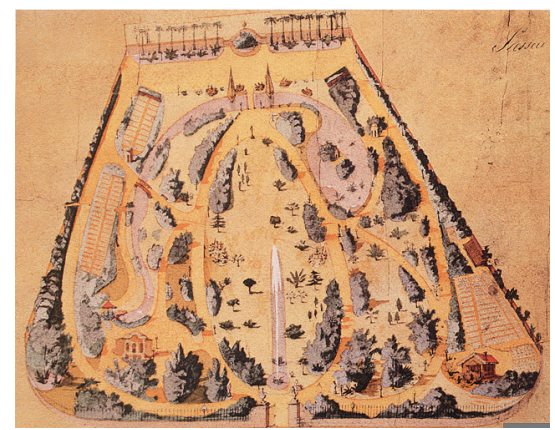

Figura 2 - O Passeio Público de Glaziou, desenho datado de 1879 e atribuído a Glaziou Fonte: Acervo Fundação Biblioteca Nacional. 
No ano da inauguração do recém-reformado jardim público, o Almanaque Laemmert publicou uma matéria fazendo menção a numerosos detalhes que imprimiam com clareza as intervenções realizadas por Glaziou:

O estabelecimento [...] recebeu no decurso do ano próximo passado melhoramentos tais, que quase equivalem a sua completa reforma. [...] as moitas de urzas sucederam maciços de variegadas flores; [...] e milhares de outras plantas do país, e das mais remotas regiões do globo, que farão as delícias dos conhecedores, e não menos sua admiração pelo vigor com que atestarão a benignidade do céu brasileiro, sob o qual podem viver, florescer e frutificar os naturais de todos os climas, seja qual for a sua espécie, desde que recebam, ou se deem a si próprios adequado tratamento e conforto. O Passeio Público é uma miniatura do jardim paisagista, mas miniatura de mão de mestre. Largas aleias areadas, de contornos docemente curvos, o cortam em diversas direções, oferecendo a cada passo novo aspecto. Um montículo proporcionado à extensão do terreno é coroado por um pavilhão rústico, de sob o qual se tem o gozo da vista da barra e de grande parte do jardim; sua base é um rochedo áspero do qual se precipita uma nascente que se estende por cerca de 100 braças, formando um ribeiro que serpenteia por sob copadas árvores, com pequenas clareiras, até perder-se num laguinho gracioso, dentro do qual existem uma ilhota e dois escolhos. Quatro alvíssimos cisnes e alguns palmípedes do país são atualmente os habitantes dessas frescas águas [...] Consignando aqui alguns dos mais notáveis trabalhos dos Srs. Fialho e Glaziou [...], sua execução, honra à inteligência, ao gosto e à atividade dos empresários de uma obra que parece não terem calculado seus interesses pecuniários, mas os do país, de que um é natural e o outro deseja ser hóspede útil. (LAEMMERT, E.; LAEMMERT, H., 1862, p. 314)

A documentação encontrada no Muséum National d' Histoire Naturelle revela que, com a conclusão da obra do Passeio Público, em 1862, Glaziou assumiu a direção do jardim e, ali mesmo, num pequeno chalé suíço escondido entre os arvoredos, de fundos para o Largo da Lapa, fixou sua residência, a qual seria sua moradia até 1889. É interessante notar que, no desenho original, o local aonde seria sua moradia já estava representado em sua obra.

Ao longo dos anos, o Passeio Público sofreu algumas modificações, como novas estátuas e bustos de personalidades brasileiras ligadas às artes, como Gon- 
çalves Dias, Castro Alves, Olavo Bilac, Chiquinha Gonzaga e do grande Mestre Valentim. Em 1904, uma alteração significativa ocorreu no espaço através da eliminação do terraço que dava acesso direto ao mar para a construção da Avenida Beira-Mar. (HETZEL; NEGREIROS, 2011) Porém, ainda hoje, é possível identificar muitas espécies de árvores que, certamente, foram introduzidas pelo paisagista bretão, destacando-se os oitizeiros, figueiras, baobás, jequitibás, palmeiras-imperiais, paus-ferros e paus-mulatos.

Considerando que a interpretação das representações visuais visa enriquecer o estudo sobre a análise de um período histórico, e que isso se realiza através de observações do diagnóstico das imagens, buscando uma explicação descritiva do conteúdo que estas exercem, podemos considerar que o estudo dos projetos paisagísticos de Glaziou fornece à sociedade, e em especial à comunidade científica, informações sobre a atual condição dos jardins desse paisagista francês, além de divulgar a contribuição desse personagem sobre o conhecimento e uso ornamental da flora nativa, gerando subsídios para a reformulação dos parques e jardins de sua autoria.

\section{Considerações finais}

O objetivo desse estudo foi a análise da produção material e artística de dois viajantes do século XIX, no caso, William John Burchell (1781-1863) e Auguste François Marie Glaziou (1828-1906), em solo brasileiro, esclarecendo a maneira como estes observaram e registraram o espaço e a natureza do Brasil. As fontes iconográficas analisadas foram desenhos e pinturas realizadas pelos citados viajantes.

Foi possível conhecer a extensa produção material realizada pelos naturalistas, de forma a destacar não só uma vasta coleção de plantas e formação de herbários, como também a criação artística aliada ao propósito de conhecimento e representação da natureza.

Destacamos as trajetórias diferenciadas dos naturalistas Burchell e Glaziou, que possibilitaram experiências próprias, expressas através da ciência e da arte.

As fontes iconográficas foram ressaltadas pelo seu valor documental e estético e se colocam até os dias atuais passíveis de leituras interdisciplinares. Vale ressaltar que grande parte dessas imagens foi produzida em terras brasileiras, mas se encontra em coleções de museus europeus, a serem divulgadas em estudos científicos e artísticos.

\section{Referências}

\footnotetext{
ALLAIN, Y.-M. Le transportdes plantesetles jardins de ports. ALLAIN, Y.-M. et al. (Ed.). Passions botaniques: naturalists voyageur sau temps des grandes découvertes. Rennes: Ouest France, 2008. p. 33-49.
} 
AMADURO, C. D. Os jardins da Chácara do Challet: uma análise da atuação de Glaziou em Nova Friburgo. 19\&20, Rio de Janeiro, v. 6, n. 2, abr. 2009.

ARBER, A. Herbals: their origin and evolution, a chapter in the history of botany (1470-1670). Cambridge: University Press, 1912.

BEINART, W.; MIDLETON, K. Transferências de plantas em uma perspectiva histórica: o estado da discussão. Topoi, Rio de Janeiro, v. 10, n. 19, p. 160-180, jul./dez. 2009.

BETHELL, L. Dois artistas ingleses no Brasil: Charles Landseer (1825-1826) e William John Burchell (1825-1830). Revista IHGB, Rio de Janeiro, ano 173, n. 456, p. 77-96, jul./ set. 2012.

CARVALHO, M. C. W. A visão da paisagem na obra de William John Burchell (17811863). Vitruvius, [S. 1.], ano 7, 2013. Disponivel em: <http://www.vitruvius.com.br/ revistas/read/arquiteturismo/07.073/4700>. Acesso em: 7 jul. 2014.

CAMPOS, M. de F. H. Visões do Brasil através de artistas viajantes, século XIX. A Cor das Letras, Feira de Santana, n. 7, p. 177-194, 2006.

CASADEI, T. O. Glaziou e a Imperial Quinta da Boa Vista. Revista do IHGB, Rio de Janeiro, v. 348, p. 245-249, 1985.

CUNHA, M. G. O extraordinário Glaziou. Leituras Paisagísticas 2: teoria e práxis.

Rio de Janeiro, p. 46-59, 2006.

FÉE, A. L. A. Cryptogamesvasculaires (fougères, lycopodiacées, bydroptéridées, equisétacées) du Brésil. Paris: Baillière, 1869.

FERREZ, G. O Brasil do primeiro reinado visto pelo botânico William John Burchell 1825-1829. Rio de Janeiro: IHGB, 1966.

FOLLY, L. F. D. A bistória da Praça Princeza Izabel em Nova Friburgo: o projeto esquecido de Glaziou. 2007. 218 f. Dissertação (Mestrado em Urbanismo) - Faculdade de Arquitetura e Urbanismo, Universidade Federal do Rio de Janeiro, Rio de Janeiro, 2007.

FRANKLIN, A. Breve historia da Imperatriz. Imperatriz, MA: Ética, 2005. (Ciencias Humans, v. 1).

GLAZIOU, A. F. M. Notícia sobre botânica aplicada pelo Dr. A. Glaziou.In: GLAZIOU, A. F. M. The realities and potentialities of Brasilia's landscapes: from forgotten myths to the invention of the world heritage, [S.l.: s. n.], 1896.

GLAZIOU, A. F. M. Liste de Plantes Du Brésil Central Recueilles em 1861-1895. TitleBulletin de la Société botanique de France, France, v. 3, n. 52, p. 1-661, 1905

HETZEL, B.; NEGREIROS, S. Glazion e as raizes do paisagismo no Brasil. Rio de Janeiro: Manati, 2011.

KURY, L. Auguste de Saint-Hilaire, viajante exemplar. Revista Intellèctus, Rio de Janeiro, ano 2, n. 1, p. 1-11, 2003. Disponivel em: <http://www.intellectus.uerj.br/Textos / Ano2n1/Texto\%20de\%20\%20Lorelai\%20Kur.pdf>. Acesso em: 11 ago. 2014. 
KURY, L. Viajantes-naturalistas no Brasil oitocentista: experiência, relato e imagem. Historia, Ciências, Saúde - Manguinhos, Rio de Janeiro,v. 8, p. 863-80, 2001. Suplemento

LAEMMERT, E.; LAEMMERT, H. Passeio Público. Almanak. Administrativo, Mercantil e Industrial da Corte e Província do Rio de Janeiro para o ano de 1862. Rio de Janeiro, p. 313-314, 1862

LAMMY, D. Le dessin botanique dasn la transmission des connaissances. In: ALLAIN, Y.-M. et al. (Ed.) Passions botaniques: naturalists voyageurs au temps des grandesdécouvertes. Rennes: Éd. Ouest-France, 2008.

LES CLEVERLY. A short biography W. J. Burchell, special agent or naturalist? [London, Prestige Art Press, 1987]

LEMOS, C. A. C. A república ensina a morar (melhor). São Paulo: Hucitec, 1999.

LUZ, G. E. Goyaz, entre a forma e a função urbana:um estudo sobre a imagem da cidade no século XIX (1845-1880). 2012. 135 f. Dissertação (Mestrado em Historia) Faculdade de História, Universidade Federal do Goias, Goiania, 2012.

MACEDO, S. S.; SAKATA, F. G. Parques urbanos no Brasil. São Paulo: EDUSP, 2002

MCKAY, H. William John Burchell, botanist. Journal of South African Botany, Kirstenbosch, v. 7, p. 1-186, 1941.

MARTENS, G. V. Algae brasiliensis circa Rio de Janeiro a cl. A. GLAZIOU, hortipublicidirectore, botanico indefesso, annis 1869 et 1870 collectae. Videnskalige Med Deleser Dansk. Naturbistoriske Forening, [S. 1.], n. 3, p. 144-148, 1871.

MARTIUS, C. F. P. V.; EICHLER, A. G. ; URBAN, I. Flora Brasiliensis. [S. 1.]: Monachiiet Lipsiae, 1840.

MÉRIAN, J. Y. Glaziou e os jardins sinuosos. Rio de Janeiro: Dantes, 2009. (Catálogo).

MILANO, M. S.; DALCIN, E. Arborização de vias públicas. Rio de Janeiro: Light, 2000.

NORONHA, S. O Parque da Praça da República. Revista do Serviço do Patrimônio Histórico e Artístico Nacional, Rio de Janeiro, n. 18, p. 102-163, 1944a.

NORONHA, S. Traços Bibliográficos de Auguste François Marie Glaziou. Revista do Serviço do Patrimônio Histórico e Artístico Nacional. Rio de Janeiro, n. 18, p. 164-172, 1944b.

OLIVEIRA, K. C. Paramentros urbanísticos na conformação e proteção do patrimônio urbano. In: CONGRESSO INTERDISCIPLINAR EM SOCIAIS E HUMANIDADES. 2., 2013. Belo Horizonte. Anais... Belo Horizonte: CONINTER, 2013.

PERROTA, I. Desenhando um paraíso tropical: a construção do Rio de Janeiro como um destino turístico. 2011. 217. Tese (Doutorado em Historia, política e Bens Culturais) Centro de Pesquisa e Documentação de História Contemporânea do Brasil, Fundação Getúlio Vargas, Rio de Janeiro, 2011.

POULTON, E. B. William John Burchell. London: Spottswood \& Co. Ltd, 1907.

PRESTES, M. E. B.; OLIVEIRA, P. ; JENSEN, G. M. As origens da classificação de plantas de Carl Von Linné no ensino da biologia. Filosofia e Historia da Biologia, 
São Paulo, v. 4, p. 101-137, 2009. Disponível em: <http://www.abfhib.org/FHB/FHB04/FHB-v04-04.html>. Acesso em: 9 jan. 2015.

ROBBA, F.; MACEDO, S. S. Praças Brasileiras. São Paulo: EDUSP: Imprensa Oficial do Estado, 2002.

SALGADO, I.; PICCINATO JUNIOR. D. Terra urbana: a relação das instituições religiosa e publica no controle do patriotismo fundiário original da cidade de Buritizal/ SP. Cadernos PROARQ, Rio de Janeiro, n. 18, p. 238-258, 2012.

SANJAD, N.R. Nos jardins de São José: uma historia do Jardim Botanico do Grão Pará, 1796-1873. 2001. 213 f. Dissertação (Mestrado em Geociencias) - Instituto de Geociências, Universidade Estadual de Campinas, Campinas, 2001.

SEGRE, R. et al. Os panoramas multi-layer: um hiperdocumento iconográfico da historia da cidade do Rio de janeiro. In: CONGRESSO DA SOCIEDADE IBEROAMERICANA DE GRÁfICA DIGITAL, 13., 2009, São Paulo. Anais... São Paulo: SIGRADI, 2009.

STEARN, W. T. An introduction to the species plantarum and cognate botanical works of Carl Linnaeus. London: printed for the Ray Society; sold by Quaritch, 1957.

STEWART, R.; WARNER, B. William John Burchell: the multi-skilled polymath. South Africa Journal Science, Johannesburg, v. 108, n. 11-12, 2012. Disponivel em: <http:// www.sajs.co.za/sites/default/files/publications/html/1207-10766-1-PB.html>. Acesso em: 12 jan. 2014.

TERRA, C. G. Os jardins no Brasil no século XIX: Glaziou revisitado. 2. ed. Rio de Janeiro: EBA/UFRJ, 2000

TOGNON, M. O desenho e a historia da técnica na arquitetura do Brasil colonial. Varia Historia, Belo Horizonte, v. 27, n. 46, p. 547-556, jul./dez. 2011.

VALENTE, M. C. et al. O jardim do passeio público do Rio de Janeiro. Paisagismo. Rodriguésia, n. 31, p. 235-319, 1979 